\title{
Telenovela e realidade social: algumas possibilidades dialógicas ${ }^{1}$
}

Maria Lourdes Motter

Livre-docente do Departamento de Comunicações e Artes da ECA-USP e vice-coordenadora do Núcleo de Pesquisa de Telenovela da ECA-USP, atuando como orientadora de pós-graduação: mestrado e doutorado. Autora de diversos artigos e obras como Ficção e realidade: a construção do cotidiano na telenovela $e$ Ficção e história: imprensa e construção da realidade.

E-mail: lumotter@ig.com.br.

Daniela Jakubaszko

Mestra em Ciências da Comunicação pela Escola de Comunicações e Artes da Universidade de São Paulo com a dissertação Telenovela e experiência cotidiana: interação social e mudança (São Paulo, 2004).

E-mail: ocadani@yahoo.com

A partir do tema geral deste congresso, Ensino e Pesquisa em Comunicação, pensamos que esta fosse uma oportunidade para trazer para reflexão neste núcleo de pesquisa de ficção seriada algumas categorias de análise que surgiram durante a pesquisa Ficção e realidade: a construção do cotidiano na telenovela ${ }^{2}$, e que foram também exploradas na pesquisa de mestrado Telenovela e experiência cotidiana: interação social e mudança. Acreditamos que haja nesses trabalhos algo diferente do que se tem feito no âmbito da pesquisa em comunicação. Atualmente, com um campo firmado e com as miríades de possibilidades combinatórias teóricas e metodológicas para construção de objetos de estudo, é possível traçar diferentes caminhos e, quem sabe, o que estamos tentando construir possa contribuir para a pesquisa em comunicação, mais particularmente com a pesquisa de ficção televisiva.

Advindas, principalmente, dos paradigmas das ciências sociais, as teorias da comunicação compõem hoje um universo plural de opções para se estudar os fenômenos da Comunicação. Diversificam-se teorias, abordagens, métodos e técnicas para alcançar uma compreensão cada vez mais lúcida de seus objetos eleitos e de suas relações com as culturas e sociedades. Assumem-se diferentes campos de estudo, hipóteses, objetos e objetivos; modelos de processos comunicativos e respectivos modelos teóricos, âmbitos de pesquisa e pressupostos

1. Trabalho enviado ao NP 14 - ficção seriada, do V Encontro dos Núcleos de Pesquisa da Intercom, XXVIII Congresso Brasileiro de Ciências da Comunicação.

2. MOTTER, M. L. Ficção e realidade: a construção do cotidiano na telenovela. São Paulo: Alexa Cultural, Comunicação e Cultura - Ficção Televisiva, 2003. 
3. WOLF, M. Teorias da comunicação. Lisboa: Editorial Presença, 1995.

4. LOPES, M. I. V.; BORELLI, S. H. S.; RESEN$D E, V$. R. Vivendo com a telenovela: mediações recepção, teleficcionalidade. São Paulo: Summus, 2002. p. 27-29.

5. SILVERSTONE, Roger Por que estudar a mídia? São Paulo: Loyola, 2002. sociológicos. Realizam-se pesquisas administrativas, empíricas e crítico-teóricas, conforme as tradições americanas ou européias ${ }^{3}$. A interdisciplinaridade acaba sendo uma exigência natural para o pesquisador que se dedica a este tipo de investigação.

Tal caráter interdisciplinar por excelência das ciências da comunicação pode ser observado através, por exemplo, da leitura dos trabalhos existentes sobre o objeto telenovela. São pesquisas que versam sobre os mais diversos temas, como sua historiografia, processos de produção, comercialização, estética, autoria, questões de gênero, seu universo discursivo, simbólico; pode-se abordá-la como entretenimento e informação, como nutriente do imaginário, como catarse social; pode-se estudar os impactos sociais, as técnicas de persuasão, a utilização que faz de estereótipos e preconceitos, enfim, qualquer que seja o recorte, disciplinas como a sociologia, a antropologia, a psicologia, a semiótica, a filosofia etc. vêm auxiliar a construção do objeto.

Além disso, para cada um destes aspectos privilegiados para investigação pode-se assumir uma das tradições de estudo ou, na medida do possível, combiná-las entre si: a tradição dos estudos de recepção, de crítica semiótica ou literária, das pesquisas de usos e gratificações, dos efeitos e dos estudos culturais ${ }^{4}$. Dentro de cada uma destas perspectivas, multiplicam-se as abordagens conforme forem entrelaçados os pressupostos teóricos, conceituais, metodológicos e técnicos.

Os estudos existentes no campo das ciências da comunicação, a nosso ver, já comprovam, por diversos caminhos, a influência que os meios exercem sobre a sociedade ou sobre os indivíduos que a compõem. Os estudos de recepção na linha de pesquisa das mediações (Martín-Barbero, Canclini, Lopes), por exemplo, mostram que há mais que influência, há troca de saberes, há experiências no contexto das subjetividades com os meios. Dessa forma, o que nos inquietava era o fato de como a articulação sociedade-meios-sociedade-meios, num movimento dialético, polifônico e dialógico, direciona, inventa, desenha os consensos, os novos consensos e as transformações das práticas e experiências cotidianas.

Partimos do pressuposto, dado por Silverstone ${ }^{5}$, de que é no senso comum que se deve fundamentar o estudo das mídias. Nesse contexto, a telenovela passa a ser vista como documento de época, como enunciação que participa da construção de memórias coletivas, visto que a memória - esta narrativa voltada à composição de identidades e sentidos - está intimamente relacionada com as imagens construídas por nós do (e no) presente, as quais se mantêm e transformam-se através da participação na arena de conflitos, que é a do debate pela hegemonia social. Passa a ser vista também, principalmente no Brasil, como um dos discursos que ajudam a alimentar a opinião pública e a estabelecer consensos.

Apoiamo-nos em Bakhtin, Gramsci e Heller para entender o senso comum e a ideologia do cotidiano; nas reflexões de Halbwachs, Le Goff, Novaes, entre outros, para compreender nosso objeto de estudo como memória coletiva.

Perguntamos como essas produções televisivas de longa duração, consideradas por muitos um produto alienante, contribuem para legitimar, estimular ou inibir as novas práticas sociais. Procuramos saber como se inserem no debate 
Telenovela e realidade social - Maria Lourdes Motter e Daniela Jakubaszko

sobre temas de importância social instaurado no ambiente social e como interagem com ele. Nosso objetivo era verificar modos possíveis de interação entre a telenovela e a vida social brasileira nos processos de aceitação, incorporação e transformação das práticas e experiências cotidianas.

Para tentar responder a nossas indagações, consideramos que a ficção constrói um mundo paralelo tomando como referente a própria realidade em que está inserida e da qual é representante. Aceitamos considerar, em primeiro lugar, que a ficção é uma dimensão constituinte do processo de construção da realidade social e que, ao mesmo tempo, toma desta última os elementos necessários para sua construção e composição: palavra, roteiro, ação dramática, direção, atuação, cenários, figurinos, iluminação, tomadas de câmera, iluminação, cortes de edição, sonorização, entre outros.

Em certa medida, o real aparece sempre como referente, se não tanto da narrativa, pelo menos dos elementos que compõem as ações e tornam verossímeis os lugares, as personagens e ações; o onde, como, quem, o quê e quando. A ficção é construída de maneira a ganhar uma inteireza que lhe dota da aparente independência do contexto em que está inserida.

Assim, por uma opção metodológica, que em seu percurso pretende retornar à interação ficção/realidade, e como um recurso didático utilizado para fins analíticos foi preciso que se considerassem, num primeiro momento, a ficção e a realidade em dois planos distintos: o cotidiano ficcional, a realidade paralela e o cotidiano concreto, da vida prática, da experiência cotidiana, da realidade factual.

Para este último realizamos uma pesquisa no ambiente social, observando algumas manifestações discursivas não-ficcionais. Dessa forma, dentro deste universo, recorremos ao discurso científico, médico, jurídico e formulações de políticas governamentais sobre os assuntos estudados - como manifestações do discurso oficial -, e ao discurso da mídia, representado por algumas das revistas de maior circulação do país - como manifestação discursiva dos níveis superiores da ideologia do cotidiano $^{6}$ (Bakhtin). Buscamos também as expressões verbais e concepções presentes no senso comum, ou melhor, nos níveis inferiores $d a$ ideologia do cotidiano. Com a observação destes três níveis discursivos presentes no ambiente social, evidenciamos diferentes visões existentes sobre os temas de investigação que constroem o contexto em que se inserem e com o qual dialogam as telenovelas. Assim pudemos avaliar as contribuições da telenovela brasileira para nosso contexto social.

Entretanto, o que nos interessa neste momento não é defender o que poderíamos chamar de teoria das interações, mas sim refletir sobre as categorias de análise criadas para estudar o mundo ficcional. Para analisar a telenovela, partimos do percurso metodológico da ingenuidade consentida, que consiste em pensar, sentir, ver a telenovela pela perspectiva do telespectador-observador, como num processo de pesquisa da observação participante.

Para a telenovela, também por opção metodológica, temos distinguido duas dimensões: a melodramática e a social. E essa seria a dimensão social, o aspecto

6. BAKHTIN, M. Marxismo e filosofia da linguagem São Paulo: Hucitec, 1992. p. $118-120$. 
7. LARROSA, J. A novela pedagógica e a pedagogização da novela. In: LARROSA, J. Pedagogia profana: danças, piruetas e mascaradas. Belo Horizonte: Autêntica, 1999. p 117-138.

8. Ibid., p. 118

9. Ibid., p. 123

10. Ibid., p. 123. da telenovela brasileira - para além dos aspectos técnicos e tecnológicos - que mais diferencia as nossas produções daquelas puramente melodramáticas.

De modo análogo, Larrosa ${ }^{7}$ identifica dois discursos predominantes na estrutura da novela literária: o poético e o pedagógico. Ora, se a telenovela é mais um dentre os diversos discursos que povoam a realidade e se ela, enquanto gênero, apóia-se no cotidiano, deve-se lembrar que, como este, ela desdobra-se em múltiplos discursos. O que mais interessa neste momento é o discurso de caráter pedagógico.

Larrosa discorre sobre o tema tomando como ponto de partida o conceito de texto pedagógico formulado por Basil Bernstein e a observação de alguns trechos de $O$ Nascimento da Tragédia de Nietzsche. Na seção quatorze dessa consagrada obra, busca a genealogia da literatura didática, aquela que apresenta, em sua estrutura, a dimensão poética construída e orientada pela dimensão teórico-filosófica, nestes termos:

Nietzsche identifica literatura didática e novela, ou melhor, qualifica a novela como o gênero poético que melhor expressa o espírito teórico. O teórico em arte, em contraste com o trágico, caracterizar-se-ia por sua pretensão de verdade e, a partir daí, por sua pretensão de justiça. A novela seria, então, o gênero "moral" por excelência: um gênero "otimista" e "progressista", impulsionado pela confiança na inteligibilidade da existência humana e na possibilidade de sua reforma ${ }^{8}$.

O filósofo, então, observando uma relação de dependência entre a literatura e a dialética, encontra, nos diálogos de Platão, a origem da forma literária que terá, mais adiante, a novela como musa. A relação legitima-se de vez que ambos elegem a forma diálogo. Como ressalta Larrosa, Nietzsche, antecipando o dialogismo bakhtiniano, concebe o diálogo como uma forma de expressão que mistura todos os estilos e formas existentes, caracterizando-se como um gênero híbrido e excêntrico, referindo-se, o autor, à mistura entre lírica, drama e narrativa, prosa e poesia, literatura e filosofia, presente no gênero.

Seguindo essa pista e admitindo que "antes de ser uma história, a novela é uma instrução, um ensinamento, um saber", conforme afirmou Julia Kristeva em sua gênese da estrutura novelesca, Larrosa considera que há na estrutura da forma diálogo a encarnação de um logos pedagógico, definindo-o como aquele

[...] que funciona através de um jogo aberto e excêntrico, nunca fechado e nunca centrado, de três elementos que constantemente interferem entre si. Em primeiro lugar, a vida concreta, espacial e temporalmente determinada, sempre plural e complexa, em que se desenvolvem os protagonistas. Em segundo lugar, um tecido dialógico híbrido, ou um jogo excêntrico entre discursos heterogêneos. Em terceiro lugar, um impulso na direção da verdade e da justiça, ou uma suscetibilidade compartilhada pelo conhecimento e pela melhoria do humano ${ }^{10}$.

Entretanto, faz uma ressalva, uma distinção entre dois tipos possíveis de encarnação do logos pedagógico. O primeiro seria aquele que convida o leitor à reflexão. Quando o diálogo é um convite ao pensar, leva o leitor a uma experiência, uma vivência, que se realiza em última estância como aprendizagem e transformação. O segundo, ao contrário, assume uma forma monológica, 
Telenovela e realidade social - Maria Lourdes Motter e Daniela Jakubaszko

unívoca e dogmática, de maneira a fechar qualquer possibilidade de reflexão, portanto, de transformação.

De qualquer maneira,

[...] a novela pedagógica não seria outra coisa que um instrumento poeticamente sofisticado para persuadir ou convencer o leitor da verdade de alguma coisa e, se essa verdade for do tipo moral, para exortá-lo a atuar de determinada maneira. Por outro lado, a novela seria basicamente comunicativa, no sentido de que a relação entre o autor e o leitor seria similar à que existe entre um professor e seu aluno, um pregador e sua audiência ou um orador e seu público. O emissor teria um projeto explícito sobre o destinatário e tentaria assegurar-se da eficácia da transmissão, isto é, da realização sem desvios de seu projeto ${ }^{11}$.

É importante abrir um parêntese para esclarecer o que o autor quer dizer quando usa a palavra verdade. De fato, o que parece estar em jogo não é tanto a verdade, mas sim um valor a ela atribuído, o qual deverá ter como referência seu serviço em favor das inquietações que impulsionam à liberdade, ou em proveito do conformismo que leva ao servilismo e à submissão.

Se, como afirma Larrosa, a novela é um discurso de caráter híbrido e excêntrico, por isso constitui "um jogo constante de interferências entre níveis que, justamente porque diferem entre si, são capazes também de se interferirem e desestabilizarem-se mutuamente" 12 .

Assim, as categorias propostas visam, principalmente, à dimensão social das telenovelas, a fim de encontrar um modo de avaliar como elas focalizam os temas que elegem para inserir em suas histórias e, de acordo com sua intensidade, descobrir quando a ficção tem maior força de diálogo com o ambiente social. Mas não se pode desprezar, tão pouco negligenciar, os outros elementos que compõem a telenovela e que são igualmente responsáveis pelo seu êxito ou fracasso. A ênfase na dimensão pedagógica é apenas um recurso metodológico que pretende facilitar o processo investigativo: um olhar que busca nela própria, analisando-a por dentro, os caminhos teóricos para compreendê-la como objeto específico.

É importante esclarecer que temas de importância social são aqueles que, em determinado momento histórico, refletem inquietações, geram questionamentos e propõem problemas a serem pensados, definidos, resolvidos pelo ambiente social em que circulam. Somos sujeitos históricos e o nosso olhar sobre o mundo foi, na verdade, por ele orientado. Conforme Bakhtin:

[...] na realidade é claro que vemos "a cidade e o mundo" através do prisma do meio social concreto que nos engloba. Na maior parte dos casos, é preciso supor, além disso, um certo horizonte social definido e estabelecido que determina a criação ideológica do grupo social e da época a que pertencemos, um horizonte contemporâneo da nossa literatura, da nossa ciência, da nossa moral, do nosso direito $^{13}$.

Cada época apresenta seus conflitos. Muitos deles ainda estão no horizonte social e não foram ainda bem trabalhados nas camadas inferiores da ideologia do cotidiano. Quando o autor/roteirista recolhe temas que ainda estão germi-

11. Ibid., p. 124

12. Ibid., p. 120

13. BAKHTIN. M. Marxismo e filosofia da linguagem. São Paulo: Hucitec, 1992. p. 112 
nando como inquietações no ambiente social, oferece uma experiência viva, através da narrativa, às mudanças não afirmadas, mas em movimento, fazendo de um esboço uma pintura.

Assim, tais categorias pretendem definir o grau de enfrentamento das questões sociais dentro da telenovela:

[...] autores consagrados, marcados por [...] intenção de mudança [...] [trabalham] com diferentes graus de enfrentamento das questões que elegem para discussão. Não só do ponto de vista do destaque conferido na hierarquia das tramas, mas nelas, o modo frontal, lateral ou tímido de tratá-las ${ }^{14}$.

Antes de explicitar as categorias que resolvemos adotar, achamos pertinente esclarecer o sentido que assume a utilização do termo temática no contexto de nossas reflexões. Via de regra, como percebemos nas leituras que temos feito sobre nosso objeto, tal palavra aparece simplesmente como um sinônimo para tema, assunto, questão. Em nossos trabalhos, temáticas referem-se a um conjunto de temas tratados na telenovela, ou seja, quando um tema ganha destaque dentro e fora da ficção, quando é bem articulado entre as dimensões social e melodramática da telenovela, desdobra-se, dando origem a uma multiplicidade de aspectos que são as várias faces e implicações do próprio tema, irradiadas de um ponto central que se conecta com diferentes ações e personagens dentro da narrativa e interfere decisivamente nos rumos da trama. No Novo Aurélio, encontramos a seguinte definição para Temática:

conjunto de temas caracterizadores de uma obra artística ou literária: "Para a poesia tradicional, cultivada desde o renascimento, a fonte de inspiração seriam os grandes autores clássicos, já admitidos como modelos de excelência, e que forneciam a temática e o sistema imagístico para ser imitados pelos nossos escritores" (Afrânio Coutinho, A Tradição Afortunada, p. 67) ${ }^{15}$.

Assim, por exemplo, para considerar a reforma agrária como temática presente na telenovela $O$ Rei do $G a d o^{16}$, foi preciso reconhecer que este tema permeava a maior parte dos núcleos e acontecimentos da ficção, bem como era discutido do ponto de vista da esfera privada/pessoal, da política, da economia, da realidade sociocultural; tudo isso através dos dilemas dos personagens e de figuras como os líderes Regino e sua esposa, do senador Caxias e seus colegas de senado, do empresário Bruno Mezenga e da sem-terra Luana. O tema, irradiado para as tramas centrais e secundárias, passou a ser

14. MOTTER, op. cit., p. 200.

15. FERREIRA, Aurélio Buarque de Holanda. Novo Aurélio: o dicionário da língua portuguesa do século XXI. 2. ed. Rio de Janeiro: Nova Fronteira, 1992. p. 1659.

16. De Benedito Ruy Barbosa e direção de Luís Fernando Carvalho, jun. 1996/fev. 1997. focalizado levando-se em conta os desdobramentos que ele de fato provoca e interfere em toda a realidade vivida pelos seres ficcionais: de tema passou a temática. Desse modo, este termo procura fazer uma distinção que evita o nivelamento quanto ao modo de focalização construída pelo autor para determinado tema; assim, insistimos, uma telenovela pode trazer qualquer tema de interesse social, mas não necessariamente fará com que ele seja considerado como temática.

Agora podemos explorar as demais categorias. Numa escala hierárquica, teríamos os seguintes tipos de focalização de temas e temáticas. 


\section{QUANDO O DEBATE É INTENSO}

1) Tematização: quando uma telenovela tematiza uma questão de importância social, quer dizer que ela assume a discussão de determinado tema de modo frontal, ocupando ele grande espaço e importância dentro da trama; torna-se, durante toda a telenovela, ou em grande parte dela, o foco central. Nesta categoria podemos ter certeza da existência de uma temática dentro da ficção. Às vezes pode estar numa trama secundária, mas percorre toda a duração da narrativa, sendo discutido com propriedade pelo autor. Comumente, pesquisas são realizadas pela emissora a fim de atingir qualidade e fidelidade no resultado. É principalmente através da análise das questões tematizadas que se pode identificar o projeto formulado pelo autor e sua respectiva proposta de solução. São também, normalmente, os temas mais irradiados para o debate público, aparecendo com recorrência na mídia em geral e até em outros setores da sociedade. Muitas vezes a tematização acaba funcionando como uma verdadeira campanha social, o que nos faz confundi-la com o chamado merchandising social; mas deixamos esse assunto para ser explorado em outro momento. Como exemplo de tematização, podemos citar a telenovela $O$ Rei do Gado com a questão da reforma agrária.

A hipótese do agenda-setting preocupa-se menos com o poder persuasivo dos meios e mais com o fato de que estes, por realizarem a mediação entre os sujeitos e o mundo em que vivem, lhes apresentam uma lista que define os tópicos sobre os quais se deve ter uma opinião e saber discutir a respeito, bem como as categorias em que se pode organizá-los num esquema hierárquico. Seu pressuposto fundamental é o de que o contato com os meios oferece grande parte da compreensão que as pessoas têm da realidade social. Se podemos considerar a hipótese da telenovela como agenda-setting ${ }^{17}$, a explicação de Wolf talvez nos ajude a compreender o fenômeno:

A tematização é um procedimento informativo que se insere na hipótese do Agenda-setting, dela representando uma modalidade particular: tematizar um problema significa, de fato, colocá-lo na ordem do dia da atuação do público, dar-lhe o relevo adequado, salientar sua centralidade e o seu significado em relação ao fluxo da informação não-tematizada. [...] a sua função é selecionar posteriormente [...] os grandes temas sobre os quais há que concentrar a atenção do público e mobilizá-la para a tomada de decisões ${ }^{18}$.

É importante ressaltar que devemos entender a afirmação anterior tanto em relação ao que a telenovela lança para o debate público, quanto em seu próprio movimento narrativo interno.

2) Denúncia: uma telenovela faz denúncia quando aponta para problemas presentes em nossa sociedade, dando importância à questão, mas tratando-a de modo menos frontal e mais lateral. $\mathrm{O}$ roteirista passa pelo tema, flagra suas mazelas, suas conseqüências, mas pode não aprofundar o debate, nem encaminhar uma proposta de solução. Mostra a indignação dos autores com relação a certas práticas. Por exemplo, O Fim do $M u n d o^{19}$ denunciou a corrupção e o sensacionalismo da mídia. Este tipo de focalização acompanha o desenvolvimen-
17. WOLF, op. cit., p. 130158.

18. Ibid., p. 146.

19. De Dias Gomes e direção de Paulo Ubiratan, maio/jun. 1996. 
to da telenovela; não tem propriamente uma influência direta no desenrolar de acontecimentos - como no caso das questões tematizadas -, mas interfere neles, visto que a denúncia expressa-se em situações nas quais os personagens ou vão defrontar-se com obstáculos e dificuldades ou serão, eles mesmos, os agentes causadores dos problemas.

Além disso, é comumente encontrada nas linhas que traçam o perfil dos personagens, ou seja, através da caracterização dos seres ficcionais, suas atitudes, hábitos e práticas, faz-se simultaneamente a denúncia. Em geral, portanto, há uma recorrência das cenas, sem que a questão nelas implicada constitua o foco central da narrativa televisiva, mas se destaca sua relevância no contexto da ficção e da realidade. Como ilustração, a corrupção pode ser denunciada por cenas de suborno, ameaças, espionagem etc., realizadas por personagens que ficarão marcados como corruptos, vilãos, maus-caracteres. De outro lado, a inoperância do sistema de saúde será denunciada por meio de - além daqueles que estão na raiz do problema - médicos e pacientes que, sofrendo as conseqüências, evidenciam a indignação sentida (incluindo o autor) ante a situação.

Por acompanhar o desenvolvimento da narrativa e ajudar a compor os personagens, este tipo de focalização estabelece um debate intenso, mas nem sempre será aproveitado como pauta pela mídia em geral.

\section{QUANDO O DEBATE ESTÁ PRESENTE}

3) Discussão: dentro de uma história que tem em média seis meses para ser contada, e que pode mostrar meses, anos ou décadas, diversas questões atravessam a vida dos personagens. Pode ser o aborto, a adoção, a bissexualidade, o adultério, a vida nas grandes cidades, a poluição, a violência, ou seja, pode ser qualquer item de uma lista sem fim. Dessa forma, a telenovela discute um tema quando se propõe a conversar com o público sobre ele. As discussões são inserções pontuais, normalmente com ênfase no discurso verbal. Através do diálogo entre personagens procura refletir, questionar, consolar, encontrar saídas, enfim, compartilhar com os espectadores algumas das situações que muitos deles enfrentam no dia-a-dia.

4) Crítica: este tipo de focalização pode ser percebido quando a ficção faz a crítica de valores, comportamentos e práticas sociais, mediante personagens ou situações. Normalmente é realizada com diálogos e cenas que explicitam o olhar crítico do autor sobre determinado tema. A telenovela $A$ Próxima Vítima ${ }^{20}$ criticou, por exemplo, o descaso da sociedade com relação ao menor de rua, ao pobre, ao favelado. Não necessariamente existe uma reiteração do tema.

5) Contribui: pode-se contribuir para desconstruir, por exemplo, estereótipos

20. De Sílvio de Abreu e direção de Jorge Fernando, mar./nov. 1995 e preconceitos, para denunciar, mostrar, lembrar, ressaltar etc. São inserções pontuais feitas pelos autores, ou aspectos desenvolvidos nos núcleos e tramas de menor importância na telenovela. Não raro assume caráter explicitamente 
Telenovela e realidade social - Maria Lourdes Motter e Daniela Jakubaszko

didático e educativo. Por exemplo, a telenovela $O$ Clone $^{21}$ colaborou na divulgação da campanha contra a dengue. Esse tipo de focalização é que pode, para nós, ser comumente identificado com o chamado merchandising social.

\section{QUANDO HÁ PEQUENAS INSERÇÕES, MENÇÕES PASSAGEIRAS}

Mostrar: quando não há discussão de tema nem qualquer intenção de julgamento de valor ou crítica, apenas aponta, constata a existência de determinado problema ou comportamento. Um autor pode mostrar a discriminação sem discuti-la.

Lembrar: quando eventos, fatos, elementos da realidade são diretamente mencionados nos diálogos.

Questionar: esboça dúvidas e discordância do aceito como norma ou normal pela sociedade. Localiza-se nas pequenas tramas. O Fim do Mundo, por exemplo, questionou o conceito de loucura e o celibato religioso.

Quanto aos aspectos que dizem respeito a comportamentos, condutas, valores etc., considerados positivos pelo autor, ele pode optar por: evidenciar, ressaltar, defender, valorizar.

Na verdade, qualquer tema pode merecer um destes tipos de focalização; por exemplo, o preconceito étnico pode ser tematizado, aparecer como denúncia, ser criticado enquanto prática social, ou apenas mostrado ou lembrado. É possível também se adotar mais de uma forma de tratamento para a mesma questão: ao mesmo tempo que se faz a denúncia, aproveita-se para defender ou valorizar uma conduta que mostre saber conviver com a diferença. Como não há limites bem definidos entre cada uma das categorias, o mais provável é que se associe mais de um modo de focalizar a questão, predominando uma das modalidades.

Consideramos pertinente escolher categorias que contivessem, de certo modo, traços semânticos que denotassem o modo de tratamento das questões. Assim, tematizar, discutir, criticar, denunciar são opções lexicais que visam evitar o nivelamento de diferenças de atitude dos autores frente a problemas, bem como a conseqüente variação da ênfase que possa merecer determinada questão. Colocar um tema na trama central, em tramas secundárias, com irradiações ou não daquela para estas ou vice-versa, implica valoração diferenciada que consideramos importante levar em conta. Do mesmo modo, a presença de um assunto em uma trama não é a mesma coisa que sua presença fugaz e casual em um diálogo sem conseqüências para a ação dramática. [...] Desse modo, pode-se avaliar qual obra se mostra mais ou menos interessada em contribuir para a instauração/continuidade de um debate, ou para uma tomada de posição sobre uma discussão em curso no cotidiano social. Como decorrência, diferentes compromissos com a realidade concreta se estabelecem, assim como modos de repercussão variáveis ${ }^{22}$.

No entanto, a aspiração que um autor pode apresentar em propor um debate para opinião pública não garante a relevância da questão focalizada,
21. De Glória Peres e direção de Jayme Monjardim Mário Márcio Bandarra e Marcos Schechtmann, out. 2001/jun. 2002

22. MOTTER, op. cit., p. $35-36$. 
nem dota de propriedade a discussão colocada para o telespectador. Muitos temas de importância social podem aparecer apenas como pano de fundo para o desenvolvimento da dimensão melodramática, não apresentando qualquer tentativa de enfrentamento de determinada questão. Registramos, por exemplo, em $A$ Indomada ${ }^{23}$, a presença do tema alcoolismo. Contudo, não havia nenhum indicador de intenção do autor em focalizar esse tema de modo a enfrentá-lo como sendo de importância social. Ele serviu como recurso dramático, como aspecto de composição de um dos personagens. Não houve qualquer tentativa de evidenciar e trabalhar tal tema na dimensão social da telenovela.

Acreditamos que a intensidade do diálogo com o ambiente social alcançada pelas telenovelas está em estreita relação de dependência com o grau de enfrentamento das questões, mas também para tanto não se pode esquecer ou descuidar da qualidade artística do produto. Enfatizamos que apenas a dimensão social, pedagógica, bem evidenciada, problematizada pelo roteirista através de um tratamento ficcional (poético/melodramático) adequado é que impulsiona o potencial apresentado pelo gênero de encarnação de um logos pedagógico o qual incita à reflexão, mobilizando interesse e atenção, interagindo com a sociedade como um influente interlocutor social nos processos que desenham os consensos geradores de mudanças.

Por fim, esperamos que essas categorias possam, de alguma forma, colaborar para o entendimento da ficção televisiva e de como se processa sua interação com as experiências individuais e sociais. Deixamos o debate aberto para que com novas contribuições nossos estudos possam ser úteis tanto a pesquisadores como às pessoas envolvidas no fazer televisivo, a fim de que cada vez mais a telenovela possa encontrar caminhos que levem ao seu aprimoramento e ao fortalecimento do diálogo mantido com o cotidiano brasileiro.

Resumo: Pensando no tema do congresso Ensino e Pesquisa em Comunicação, este artigo procura explicitar algumas categorias propostas para avaliar diferentes graus de enfrentamento e focalização de temas sociais nas telenovelas; elas nos ajudam a verificar modos possíveis de interação entre a telenovela e a vida social brasileira no processo de incorporação, aceleração e transformação das práticas e experiências cotidianas.

Palavras-chave: telenovela brasileira, temas sociais, focalização, tematização, categorias de análise.
Abstract: This article assumes to become explicit some categories to appraise on the way which the social themes in soapoperas to aid to verify possible ways of interaction between brazilian soap-opera and the brazilian social life in the process of incorporation, acceleration and transformation of quotidian practices and experiences.

Keywords: brazilian soap-opera, social themes, quotidian practices, social interaction, methodological categories.
23. De Aguinaldo Silva e Ricardo Linhares e direção de Marcos Paulo, fev./out. 1997. 